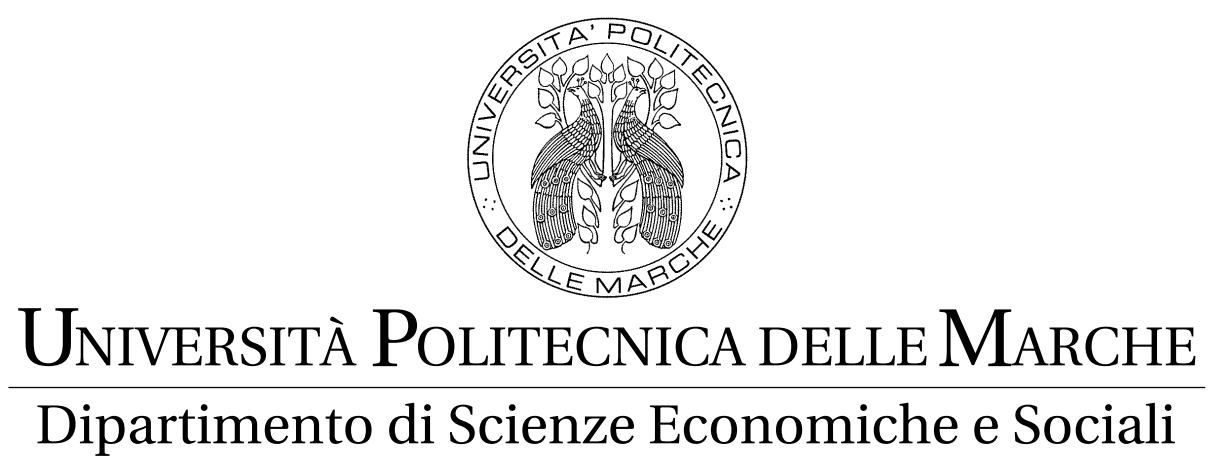

SEARCH For Profits and Business Fluctuations:

HOW BANKS' BEHAVIOUR EXPLAIN CYCLES?

Emanuele Ciola, Edoardo Gaffeo, Mauro Gallegati

QUADERNI DI RICERCA n. $450^{*}$

ISSN: 2279-9575

January 2021

(*) La numerazione progressiva continua dalla serie denominata "Quaderni di ricerca Dipartimento di economia" 
Comitato scientifico:

Giulia Bettin

Marco Gallegati

Stefano Staffolani

Alessandro Sterlacchini

Collana curata da Massimo Tamberi 


\begin{abstract}
This paper develops and estimates a macroeconomic model of real-financial markets interactions in which the behaviour of banks generates endogenous business cycles. We do so in the context of a computational agent-based framework, where the channelling of funds from depositors to investors occurring through intermediaries is affected by information and matching frictions. Since banks compete in both deposit and credit markets, the whole dynamic is driven by endogenous fluctuations in their profits. In particular, we assume that intermediaries adopt a simple learning process, which consists of copying the strategy of the most profitable competitors while setting their interest rates. Accordingly, the emergence of strategic complementarity in the behaviour of banks - mainly due to the accumulation of information capital - leads to periods of sustained growth followed by sharp recessions in the simulated economy.
\end{abstract}

JEL Class.: C15; C51; C63; E32; E44.

Keywords: Agent-based macroeconomics, Simulation-based estimation, Intermediaries behaviour, Business cycles.

Indirizzo: Emanuele Ciola (corresponding author), Department of Management, Università Politecnica delle Marche (Italy). Email: e.ciola@staff.univpm.it

Edoardo Gaffeo, Department of Economics and Management, Università degli Studi di Trento (Italy). E-mail: edoardo.gaffeo@unitn.it

Mauro Gallegati, Department of Management, Università Politecnica delle Marche (Italy). E-mail: mauro.gallegati@univpm.it 



\title{
Search for Profits and Business Fluctuations: How Banks' Behaviour Explain Cycles?†
}

\author{
Emanuele Ciola, Edoardo Gaffeo, Mauro Gallegati
}

\section{Introduction}

Credit to non-financial businesses and households is notoriously pro-cyclical (Covas and Haan, 2011; Schularick and Taylor, 2012), a fact that in the last three decades has attracted a huge amount of theoretical work meant to explore the channels linking financial flows to real macroeconomic activity (Foglia et al., 2011). The received pre-2007 approach was centred on the idea that the causality runs from changes in the real sector to movements in financial flows, whereas financial frictions impinging on the borrowers' capacity amplify the macroeconomic impact of exogenous shocks to productivity or preferences (Bernanke and Gertler, 1989; Greenwald and Stiglitz, 1993; Kiyotaki and Moore, 1997). In turn, the bulk of the research emerged after the global financial crisis has offered theories pointing toward an inversion of the causality nexus. In the models surveyed in e.g. Brunnermeier et al. (2012) and Christiano and Ikeda (2011), a shrinkage in the total amount of funds channelled from lenders to borrowers derives from disruptions in financial markets due to shocks affecting either banks' capital or liquidity. Recessions are therefore the outcome of a cut in spending and hiring by borrowers generated by a supply-induced credit tightening.

In this paper, we present an Agent-Based Model (ABM) in which the flowing of funds from savers to investors is intermediated by a stream of banks competing in fully decentralized markets for deposits and loans, and agents are imperfectly aware of the economic opportunities they potentially face. In our setting, the transmission channel between the financial and the real sectors turns out to be bidirectional, while cyclical fluctuations emerge endogenously as intermediaries adjust the size of their balance sheet to the varying competitive conditions affecting the asset and liability sides, respectively. In particular, we assume that banks compete on prices by copying the strategies of the most profitable competitors, either to attract demand deposits from households and to offer long-term - but freely severable credit contracts to firms. As a result, business cycles emerge endogenously

\footnotetext{
${ }^{\dagger}$ We thank, without implications, Prof Riccardo "Jack" Lucchetti and Dr Luca Pedini for their helpful comments.
} 
in the model because of the emergence of strategic complementarity in the behaviour of banks.

More specifically, due to information costs in locating profitable opportunities, the economy is affected by matching and allocation imperfections that co-evolve endogenously, giving rise to periods of sustained growth followed by sharp recessions. In particular, financial crises lead banks to close a large share of their credit lines, including also the most profitable ones. That, in turn, damages the long-term efficiency of capital allocation because financial institutions need time to reconstruct their portfolios of loans, producing a steady but slow recovery. In this way, the model reproduces the implicit information capital of banks (Stiglitz, 2015).

Overall, the time paths we obtain through simulations show that the statistical features of aggregate production and interest rates are in line with those observed in real data. Interestingly enough, this result is obtained in a simplified framework completely abstracting from agency frictions, aggregate disturbances to primitive parameters, time-varying risk-taking due to capital regulation or institutional arrangements like a deposit guarantee or a LOLR authority.

While close in spirit to the stream of research dealing with equilibrium search in credit markets (Diamond, 1990; Den Haan et al., 2003; Wasmer and Weil, 2004; Becsi et al., 2013), our model is firmly rooted in the tradition of the agent-based literature exploring the emergence of macroeconomic features from the localized interactions of heterogeneous agents employing decentralized matching and bargaining protocols (Fagiolo et al., 2004; Gaffeo et al., 2008, 2015; Riccetti et al., 2015; Guerini et al., 2018). This approach offers us two key advantages. First, we can extend the macroeconomic-oriented analysis of credit allocation from a static multiple equilibria framework to a dynamic one, where credit mismatches develop from feedback effects as agents interact in distinct but interrelated customer markets (Gottfries, 1991). Second, beyond overcoming the need to postulate an exogenously-given matching technology, we provide accurate econometric analyses to analyse how macroeconomic outcomes are affected by banks' behaviour in extending credit.

Lastly, our article contributes to the existing literature on ABMs introducing a novel estimation methodology (see Lux and Zwinkels (2018) and Fagiolo et al. (2019) for a review and Platt (2020) for a comparison of the available methods). In particular, we combine the well-established techniques deriving from the Method of Simulated Moments $(\mathrm{MSM})^{1}$ with the newly introduced Bayesian estimators of ABMs (Grazzini et al., 2017; Delli Gatti and Grazzini, 2019). More specifically, we exploit the distribu-

\footnotetext{
${ }^{1}$ See Grazzini and Richiardi (2015) for a discussion on the topic and Gilli and Winker (2003), Winker et al. (2007), Franke (2009), Franke and Westerhoff (2012), Recchioni et al. (2015), Mandes and Winker (2017), Chen and Lux (2018), and Bargigli et al. (2020) for different applications on financial and macroeconomic ABMs.
} 
tional properties of the MSM criterion function to generate the Bayesian posterior distributions of the structural parameters of the model. As a result, our methodology allows overcoming the analytical and computational complexity of finding the minimum of the criterion function and provides a comprehensive set of statistics for the parameters and for the goodness of fit of the model.

The rest of the paper is organized as follows. Section 2 presents the model and provides a discussion of the initial conditions used in simulations. Section 3 introduces the estimation procedure and describes the results obtained from United States (US) data. Section 4 takes stock of simulations to highlight the existence of endogenous and co-evolving business and financial cycles. Section 5 concludes and outlines directions for further research.

\section{Model}

The main purpose of this work is to investigate the role of banks' search for profits in generating endogenous business cycles. We develop a macroeconomic model with a stylised financial sector and estimate its structural parameters on US data. Subsequently, we study the response of the simulated economy to an increase in the deposit and credit markets interest rates, analysing the effects of banks' decisions on the dynamic of the shock. In this section, we define the main characteristics of the model, focusing on the sequence of events and the behaviour of the agents.

\subsection{Overview}

The economy is composed of a fixed number of households $\left(h=1, \ldots, n_{h}\right)$, financial intermediaries ${ }^{2}\left(i=1, \ldots, n_{i}\right)$ and firms $\left(f=1, \ldots, n_{f}\right)$. We assume for simplicity that agents interact in only two decentralized markets: deposit and credit. Households invest their capital in financial institutions (deposit market), while firms demand credit from banks (credit market). As a result, the system evolves through the decentralized interactions of those agents (see, among others, Delli Gatti et al., 2005; Tesfatsion, 2006).

Households are the owners of financial capital, which we assume for simplicity as the only factor of production in the economy. They cannot invest directly in producing firms or employ their wealth in home production. Conversely, we suppose that investments evaluation and ex-post verification are costly and intermediaries are more efficient than households in performing those tasks. Furthermore, we assume that banks can issue and manage loans without sustaining any additional effort or expense. Consequently, households have the incentive to deposit their wealth in financial intermediaries

\footnotetext{
${ }^{2}$ In the text, we will use the terms financial intermediaries, financial institutions and banks interchangeably.
} 
and receive a positive interest rate, which is, in turn, their only source of income.

Firms employ capital in a production function with decreasing marginal returns to produce a homogeneous good. Nevertheless, they have no resources of their own and must raise funds in the credit market to produce. Moreover, we assume that firms are heterogeneous in their level of productivity and intermediaries cannot observe it ex-ante. In other words, financial institutions do not know in advance the actual return of loans, but can only assess it after their issuance. Consequently, the efficiency of capital allocation increases over time. In fact, intermediaries have the incentive to keep in their portfolios only the most profitable loans to maximize their profits. However, that requires to identify the most productive firms, which is a time-consuming activity as the most efficient companies represent only a small share of the total ${ }^{3}$. At the same time, financial crises lead banks to close a large part of their credit lines, including also the optimal ones. That, in turn, has a long-term negative effect on the efficiency of capital allocation because financial institutions need time to reconstruct their portfolios of loans. In this way, our model can reproduce the implicit information capital of banks introduced by Stiglitz (2015).

Lastly, the role of intermediaries is to maximize their profits, balancing the demand for credit with the supply of deposits. However, contrary to the representative agent solution, the achievement of that result in the ABM introduced here requires the definition of some additional rules.

First, intermediaries set the interest rates in the deposit and credit markets considering the behaviour of competitors. Specifically, we assume that financial institutions can observe the strategy pursued by another bank in the system and copy it if it returns higher profits. In this way, we postulate a simple learning process for intermediaries, allowing the economy to converge endogenously to a pseudo-steady-state. The mark-ups in the deposit and credit markets then emerge from the monopolistic competition among banks.

Second, financial institutions may face unexpected withdrawals of deposits since households are free to reallocate their capital in the economy. When banks suffer an excessive reduction in their liabilities (i.e. total deposits are lower than the credit issued to firms), they must close part of their credit lines, starting from the less profitable ones. In this way, the efficiency of capital allocation increases over time as intermediaries will keep financing only the most productive firms.

Overall, the system evolves following the subsequent steps in each period:

1. The economy starts with the set of deposit and credit relations inher-

\footnotetext{
${ }^{3}$ In other words, new credit issuances can return both high and low interest rates, but banks have the incentive to keep in their portfolios only the most profitable ones, which are only a small share of the total.
} 
ited from the preceding period;

2. Firms produce and pay interest on loans;

3. Households receive interest on deposits, consume and save;

4. Intermediaries calculate profits, observe the strategy of competitors and set interest rates on the credit and deposit markets for the subsequent period;

5. Households observe the new interest rate and reallocate capital;

6. Intermediaries assess their net asset position and close credit in excess;

7. Firms observe the new interest rate and borrow, conditional to the availability of funds in the selected intermediary.

\subsection{Agents Behaviour}

\subsubsection{Households}

Households are the owners of financial capital and their objective is to allocate wealth to maximize the expected discounted flow of current and future consumption. We assume for simplicity that each household invests his/her capital $\left(k_{h, t}\right)$ in only one intermediary at a time as a demand deposit and receives the interest rate:

$$
r_{h, t}=r_{i, t} \quad \text { with } \quad\left\{k_{h, t}\right\} \in H_{i, t}
$$

where $r_{i, t}$ and $H_{i, t}$ are the return and the set of deposits of the $i$-th bank at the beginning of the time $t$.

Given the interest rate $r_{h, t}$, each household maximizes the inter-temporal problem:

$$
\begin{aligned}
& \max _{\left\{c_{h, t+s} ; k_{h, t+s+1}\right\}_{s=0}^{\infty}} E_{t}\left[\sum_{s=0}^{\infty}(\beta)^{s} \log \left(c_{h, t+s}\right)\right] \\
& \text { s.t. } \quad k_{h, t+s+1}+c_{h, t+s}=\left(1+r_{h, t+s}\right) k_{h, t+s}
\end{aligned}
$$

where $c_{h, t+s}$ and $k_{h, t+s}$ are consumption and savings of the $h$-th household at the time $t+s$. Accordingly, the optimal solution is given by the equations:

$$
\begin{gathered}
c_{h, t}=(1-\beta)\left(1+r_{h, t}\right) k_{h, t} \\
k_{h, t+1}=\beta\left(1+r_{h, t}\right) k_{h, t}
\end{gathered}
$$

Notice that consumption is an increasing function of the interest rate received on savings. Households have thus the incentive to search and select the intermediaries paying the highest return. Nevertheless, we recognize 
that the presence of switching costs may prevent consumers from reallocating capital in the short-term (see, among others, Sharpe, 1997; Kiser, 2002; Chakravarty et al., 2004; Brunetti et al., 2016). Accordingly, we assume that each household can compare the interest rate promised from his/her current institution $\left(r_{\mathrm{old}, t+1}\right)$ with another bank chosen at random $\left(r_{\text {new }, t+1}\right)$ only with probability $\pi_{h}$. He/she can then reallocate his/her capital to the new intermediary if it offers a higher interest rate $\left(r_{\text {new }, t+1} \geq r_{\text {old }, t+1}\right)$.

In other words, the set of deposit relations between households and intermediaries evolves according to the rule:

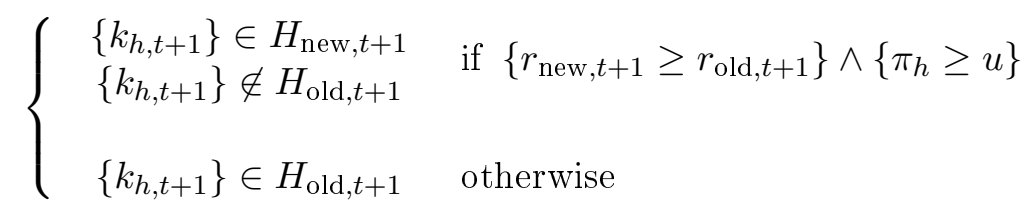

where $u \sim U(0,1)$ is a uniform distribution between zero and one.

\subsubsection{Firms}

Firms require capital to produce a homogeneous good. Nevertheless, they have no resources of their own and must borrow from one intermediary at a time to produce. Moreover, we assume that firms are bounded rational and their objective is to maximize only their future level of profits $P_{f, t+1}$ or, similarly, minimize the interest rate:

$$
r_{f, t+1}=\frac{z_{f}\left(k_{f, t+1}\right)^{\alpha}-P_{f, t+1}}{k_{f, t+1}} \quad \text { with } \quad\left\{k_{f, t+1} ; P_{f, t+1}\right\} \in F_{i, t+1}
$$

where $(k)^{\alpha}$ is a production function with decreasing marginal returns, $z_{f}$ is the exogenous productivity of the $f$-th firm, $k_{f, t+1}$ and $P_{f, t+1}$ are the size of the loan and the contractual profit of the $f$-th firm at the time $t+1$, and $F_{i, t+1}$ is the set of credit lines of the $i$-th bank at the time $t+1$.

As in Den Haan et al. (2003), we assume that credit contracts include only the size of the loan $\left(k_{f, t+1}\right)$ and the contractual profit left to the firm $\left(P_{f, t+1}\right)$. Consequently, the interest rate paid by each enterprise to its corresponding intermediary is equal to the difference between its total production $z_{f}\left(k_{f, t+1}\right)^{\alpha}$ and the (contractually) retained profit $P_{f, t+1}$. Lastly, we assume that firms have a fixed and heterogeneous level of productivity. We extract this value from a uniform distribution between zero and two at the beginning of the simulation and keep it constant over time:

$$
z_{f, t}=z_{f, 0}=z_{f} \sim U(0,2) \quad \forall t=1, \ldots, T
$$

As stated before, firms have the incentive to search and select the intermediaries promising the highest contractual profits. Nevertheless, we recognize that switching from a bank to another one is similar to ceasing the 
existing investment - if present - and starting a new one. In that sense, the empirical evidence shows that the credit market is far from being frictionless (Kim et al., 2003). For example, the presence of information asymmetries may prevent banks from lending to new borrowers or lead them to credit rationing (Jaffee and Russell, 1976; Stiglitz and Weiss, 1981). Moreover, new investment ideas are not always feasible and usually are the result of long-term decisions.

With this in mind, we assume that firms can start a new credit line and close the existing one - if any - with probability $\pi_{f}$. In other words, each company compares the contractual profit promised from its current counterparty $^{4}\left(P_{\text {old }, t+1}\right)$ with another bank chosen at random $\left(P_{\text {new }, t+1}\right)$ with probability $\pi_{f}$. The firm can then start a new credit line and close the existing one if the new financial institution offers a higher contractual profit and has sufficient resources to lend:

$$
\left\{P_{\text {new }, t+1} \geq P_{\text {old }, t+1}\right\} \wedge\left\{L_{\text {new }, t+1} \geq \bar{k}_{t+1}\right\}
$$

where $L_{\text {new }, t+1}$ are the resources available in the new intermediary, and $\bar{k}_{t+1}$ is the size of a new loan issued at the time $t$ and starting to pay interest in the subsequent period ${ }^{5}$.

In other words, the set of credit relations between firms and banks evolves according to the rule:

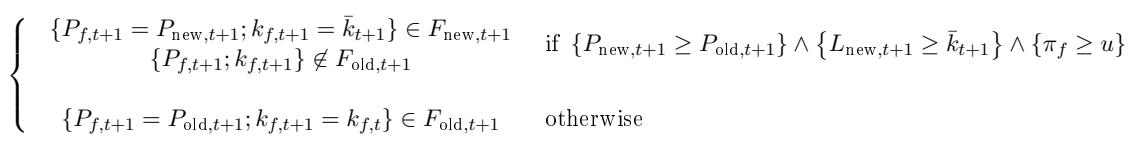

where $u \sim U(0,1)$ follows a uniform distribution between zero and one.

Notice that the size of the credit line remains the same when the firm refinances itself from its current counterparty $\left(k_{f, t+1}=k_{f, t}\right)$, while it changes when the company switches to a new bank $\left(k_{f, t+1}=\bar{k}_{t+1}\right)$ (i.e. when it starts a new investment). Indeed, we assume that intermediaries set the size of loans at the beginning of the open-ended credit relation and do not modify it over time. At the same time, they can close a credit line in any moment if they require additional resources to repay depositors. Conversely, as we will explain in the next section, banks adjust their contractual profits (i.e. the interest rate of the credit market) every period, following the behaviour of competitors.

\subsubsection{Intermediaries}

The objective of intermediaries is to maximize profits, balancing the demand for credit with the supply of deposits. We assume for simplicity that they

\footnotetext{
${ }^{4}$ Firms with no credit lines have: $P_{\text {old }, t+1}=0$.

${ }^{5}$ We will return on these values in the next section.
} 
cannot accumulate capital and transfer all their gains and losses to a third party owner. Therefore, the latter guarantees the payment of the risk-free interest rate to depositors, covering unexpected reductions in banks' profitability and avoiding their default ${ }^{6}$.

In this section, we explain the behaviour of financial institutions, focusing on the mechanism of price setting in the deposit and credit markets, the equilibrium of intermediaries' balance sheets and the supply of credit.

\section{Contractual Profits and Interest Rates}

At the beginning of every period, intermediaries assess their net profits, which are equal to the difference between the amount received from borrowing firms and the interest paid to depositors:

$$
\Pi_{i, t}=\sum_{\left\{P_{f, t} ; k_{f, t}\right\} \in F_{i, t}}\left[z_{f}\left(k_{f, t}\right)^{\alpha}-P_{f, t}\right]-r_{h, t} \sum_{\left\{k_{h, t}\right\} \in H_{i, t}} k_{h, t}
$$

where:

- $P_{f, t}=P_{i, t}=\mu_{i, t}^{f}\left(\bar{k}_{t}\right)^{\alpha}$ with $\left\{P_{f, t} ; k_{f, t}\right\} \in F_{i, t}$ is the contractual profit left by the $i$-th intermediary to its borrowers at the time $t$;

- $r_{h, t}=r_{i, t}=\mu_{i, t}^{h}\left(\bar{k}_{t}\right)^{\alpha-1}$ with $\left\{k_{h, t}\right\} \in H_{i, t}$ is the interest rate paid by the $i$-th intermediary to its depositors at the time $t$;

- $\bar{k}_{t}=\frac{\sum_{h=1}^{n_{h}} k_{h, t}}{n_{f}}$ is the size of a new loan, common to all intermediaries, issued at the time $t-1$ and starting to pay interest in the subsequent period.

In other words, financial institutions set the interest rate $\left(r_{i, t+1}\right)$ and the contractual profit $\left(P_{i, t+1}\right)$ for the subsequent period $(t+1)$ as a percentage $\left(\mu_{i, t+1}^{h}\right.$ and $\left.\mu_{i, t+1}^{f}\right)$ of the expected income ${ }^{7}\left(E\left[z_{f}\left(\bar{k}_{t+1}\right)^{a}\right]=\left(\bar{k}_{t+1}\right)^{a}\right)$ produced by a new loan $\bar{k}_{t+1}$.

Every period $t$, each bank $i$ observes the net profit of a competitor $j$ chosen at random and sets the mark-ups for the deposit and credit markets following the rule:

$$
\left\{\begin{array}{cl}
\mu_{i, t+1}^{f}=\mu_{j, t}^{f} & \\
\mu_{i, t+1}^{h}=\mu_{j, t}^{h} &
\end{array} \quad \text { if } \Pi_{j, t} \geq \Pi_{i, t}\right.
$$

\footnotetext{
${ }^{6}$ Consequently, the model is not stock-flow consistent but, as we will show later in the text, the financial sector pays on average a positive profit to its external owner.

${ }^{7}$ Notice that banks cannot observe the productivity of new firms in advance but know its distribution: $z_{f} \sim U(0,2) \Longrightarrow E\left[z_{f}(k)^{a}\right]=(k)^{a}$.
} 
where $u_{c} \sim U(-1,1)$ is a uniform distribution between minus and plus one. In other words, if an intermediary observes a more profitable competitor, it copies its strategy $\left\{\mu_{i, t+1}^{f}=\mu_{j, t}^{f} ; \mu_{i, t+1}^{f}=\mu_{j, t}^{h}\right\}$, while it explores the surroundings of its current strategy in the opposite situation $\left\{\mu_{i, t+1}^{f}=\mu_{i, t}^{f}+\right.$ $\left.\gamma u_{c} ; \mu_{i, t+1}^{h}=\mu_{i, t}^{h}+\gamma u_{c}\right\}$. In this way, we postulate a simple learning process for banks, allowing the economy to converge to a pseudo-steady-state, where the mark-ups in the deposit and credit markets emerge endogenously from the monopolistic competition between financial institutions.

On the contrary, the size of a new loan $\left(\bar{k}_{t+1}\right)$ is the result of an optimization problem under uncertainty. Intermediaries cannot observe in advance their future volumes of deposits and credits. Accordingly, they set the size of a new loan from an aggregate point of view. Specifically, they maximize the expected profits of the entire financial sector, under the prudential assumption that banks do not know the actual productivity of firms and follow an average strategy $\left\{\mu_{t+1}^{h} ; \mu_{t+1}^{f}\right\}$ :

$$
\begin{aligned}
\max _{\left\{k_{f, t+1}\right\}_{f=1}^{n_{f}}} E\left[\Pi_{t+1}\right] & =E\left[\sum_{f=1}^{n_{f}}\left[z_{f}\left(k_{f, t+1}\right)^{\alpha}-P_{f, t+1}\right]-\sum_{h=1}^{n_{h}} r_{h, t+1} k_{h, t+1}\right] \\
& =\sum_{f=1}^{n_{f}}\left(1-\mu^{f}\right)\left(k_{f, t+1}\right)^{\alpha}-\sum_{h=1}^{n_{h}} r_{h, t+1} k_{h, t+1}
\end{aligned}
$$

given the balance sheet constraint:

$$
\sum_{f=1}^{n_{f}} k_{f, t+1} \leq \sum_{h=1}^{n_{h}} k_{h, t+1}
$$

and the average flow of interest paid to the households:

$$
\sum_{h=1}^{n_{h}} r_{h, t+1} k_{h, t+1}=\mu_{t+1}^{h} \sum_{f=1}^{n_{f}}\left(k_{f, t+1}\right)^{\alpha}
$$

where the potential number of firms $\left(n_{f}\right)$ and the total volume of deposits $\left(\sum_{h=1}^{n_{h}} k_{h, t+1}\right)$ are the only publicly available information.

The optimal solution is given by the condition:

$$
k_{f, t+1}=\bar{k}_{t+1}=\frac{\sum_{h=1}^{n_{h}} k_{h, t+1}}{n_{f}} \quad \forall f=1, \ldots, n_{f}
$$

which is independent ${ }^{8}$ from the average mark-ups $\mu_{t+1}^{f}$ and $\mu_{t+1}^{h}$.

As a result, the new contractual profit and the interest rate offered by the $i$-th bank for the subsequent period $(t+1)$ are equal to:

$$
\left\{P_{i, t+1}=\mu_{i, t+1}^{f}\left(\bar{k}_{t+1}\right)^{\alpha}\right\} \wedge\left\{r_{i, t+1}=\mu_{i, t+1}^{h}\left(\bar{k}_{t+1}\right)^{\alpha-1}\right\}
$$

\footnotetext{
${ }^{8}$ The Lagrange multiplier associated with the balance sheet constraint (14) is always positive: $\lambda_{t+1}^{1}=\left(1-\mu_{t+1}^{f}+\lambda_{t+1}^{2} \mu_{t+1}^{h}\right) a\left(k_{f, t+1}\right)^{(a-1)} \geq 0$.
} 
Lastly, given the new contractual profit $P_{i, t+1}$, intermediaries compute the expected return of their existing credit lines:

$$
E\left[r_{f, t+1}\right]=\frac{\left(k_{f, t}\right)^{\alpha}-P_{f, t+1}}{k_{f, t}} \quad \text { with } \quad\left\{P_{f, t+1}=P_{i, t+1} ; k_{f, t}\right\} \in F_{i, t}
$$

\section{Balance Sheet Equilibrium}

As stated before, households can observe the interest rate promised by intermediaries for the subsequent period and move from a bank to another one (see 6). Therefore, financial institutions may face an excessive withdrawal of funds. In other words, their deposits may be lower than the total amount of loans issued to firms:

$$
L_{i, t+1}^{\mathrm{def}}=\sum_{\left\{k_{h, t+1}\right\} \in H_{i, t+1}} k_{h, t+1}-\sum_{\left\{P_{f, t+1} ; k_{f, t}\right\} \in F_{i, t}} k_{f, t} \leq 0
$$

Accordingly, intermediaries in that situation must close part of their credit lines starting from the less profitable ones, until the condition:

$$
\sum_{\left\{P_{f, t+1} ; k_{f, t}\right\} \in F_{i, t}^{\text {def }}} k_{i, f}+L_{i, t+1}^{\text {def }} \geq 0
$$

is satisfied, where $F_{i, t}^{\text {def }} \subseteq F_{i, t}$ is the smallest subset of investments with minimum profitability respecting this constraint ${ }^{9}$. That implies in turn:

$$
\begin{aligned}
\left\{P_{f, t+1} ; k_{f, t}\right\} \in F_{i, t}^{\mathrm{def}} & \Longrightarrow\left\{P_{f, t+1}=0 ; k_{f, t}=0\right\} \notin F_{i, t+1} \\
\left\{P_{f, t+1} ; k_{f, t}\right\} \in\left\{F_{i, t} \backslash F_{i, t}^{\mathrm{def}}\right\} & \Longrightarrow\left\{P_{f, t+1} ; k_{f, t}\right\} \in F_{i, t+1}
\end{aligned}
$$

\section{Credit Supply}

After the reallocation of funds by the households and the closure of the credit lines in excess, the total amount of capital available for lending in each bank $i$ is equal to:

$$
L_{i, t+1}=\sum_{\left\{k_{h, t+1}\right\} \in H_{i, t+1}} k_{h, t+1}-\sum_{\left\{P_{f, t+1} ; k_{f, t}\right\} \in F_{i, t+1}} k_{f, t}
$$

We assume that firms enter at random in the credit market and intermediaries supply capital on a first-come-first-served basis. Specifically, when a firm moves from a financial institution to another one (i.e. when it satisfies 10), the two banks (new and old) must update their available funds:

$$
\begin{aligned}
& \left\{P_{f, t+1}=P_{\text {new }, t+1} ; k_{f, t+1}=\bar{k}_{t+1}\right\} \in F_{\text {new }, t+1} \Rightarrow L_{\text {new }, t+1}=L_{\text {new }, t+1}-\bar{k}_{t+1} \\
& \left\{P_{f, t+1} ; k_{f, t+1}\right\} \notin F_{\text {old }, t+1} \quad \Rightarrow \quad L_{\text {old }, t+1}=L_{\text {old }, t+1}+k_{f, t}
\end{aligned}
$$

\footnotetext{
${ }^{9}$ In other words, $E\left[r_{f, t+1}\right] \geq E\left[r_{f_{\text {def }}, t+1}\right] \forall f \in\left\{F_{i, t} \backslash F_{i, t}^{\text {def }}\right\} \wedge f^{\text {def }} \in F_{i, t}^{\text {def }}$
} 
On the one hand, the old counterparty receives its capital back and increases the resources available for lending. On the other hand, the new bank allocates part of its capital in the new credit line. Consequently, the firms entering later in the credit market will find only the less attractive financing opportunity.

\subsection{Model Initialization}

In this section, we focus on the initialization phase of the simulation. First, we assume that households have a homogeneous quantity of capital at the beginning of the simulation:

$$
k_{h, 0}=\bar{k}=\left(\frac{1-\beta}{\alpha \beta}\right)^{\frac{1}{\alpha-1}} \quad \forall h=1, \ldots, n_{h}
$$

where $\bar{k}$ is the steady-state solution of the neoclassical optimal growth path. We set this value to reduce the number of structural parameters to estimate, minimize the degree of subjectivity and speed-up the convergence of the model to its pseudo-steady-state. Specifically, if we assume a perfectly competitive economy in which all firms maximize their expected profits $E\left[P_{f, t}\right]$ given the current interest rate $r_{t}$, we have that:

$$
\max _{\left\{k_{f, t}\right\}} E\left[P_{f, t}\right]=\left(k_{f, t}\right)^{\alpha}-r_{t} k_{f, t} \Longrightarrow r_{t}=\alpha\left(k_{f, t}\right)^{\alpha-1}
$$

Subsequently, by assuming a one-to-one relation between firms and households $\left(k_{f, t}=k_{h, t}=k_{t}\right)$ and by substituting (25) into (5), we obtain the optimal growth path:

$$
k_{t+1}=\beta\left(1+r_{t}\right) k_{t}=\beta\left(\alpha\left(k_{t}\right)^{\alpha}+k_{t}\right)
$$

whose steady-state is:

$$
\bar{k}=\left(\frac{1-\beta}{\alpha \beta}\right)^{\frac{1}{\alpha-1}}
$$

Accordingly, the simulated economy will converge to a lower, but close, pseudo-steady-state value of capital.

Second, we assume that households deposit their capital $k_{h, 0}$ in a bank selected at random during the initialisation phase of the model. Hence, at the time $t=0$, we have:

$$
\operatorname{Pr}\left(\left\{k_{h, 0}\right\} \in H_{i, 0}\right)=U\left(1, n_{i}\right)
$$

where $U\left(1, n_{i}\right)$ is a discrete uniform distribution between one and $n_{i}$.

At the same time, banks set their prices for the deposit and credit market:

$$
\left\{P_{i, 1}=\mu_{i, 1}^{f}\left(\bar{k}_{1}\right)^{\alpha}\right\} \wedge\left\{r_{i, 1}=\mu_{i, 1}^{h}\left(\bar{k}_{1}\right)^{\alpha-1}\right\} \wedge\left\{\bar{k}_{1}=\bar{k}\right\}
$$


where $\mu_{i, 1}^{f} \sim U(0,1)$ and $\mu_{i, 1}^{h} \sim U(0,1)$ are extracted from a uniform distribution between zero and one.

Lastly, firms demand funds. Given that all intermediaries offer a positive contractual profits and companies have no credit lines at the beginning of the simulation $\left(P_{f, 0}=0\right)$, we allocate capital at random. In other words, we extract the initial credit relations with probability:

$$
\operatorname{Pr}\left(\left\{P_{f, 1}=P_{i, 1}, k_{f, 1}=K_{0}\right\} \in F_{i, 1}\right)=U\left(1, n_{i}\right)
$$

where $U\left(1, n_{i}\right)$ is a discrete uniform distribution between one and $n_{i}$.

\section{Estimation}

In this section, we introduce the estimation procedure of the vector of structural parameters of the model. We propose a modified (Bayesian) version of the Extended Method of Simulated Moments (EMSM) to deal with the high non-linearity of our framework and the resulting failure in calculating both the analytical and numerical derivatives. Subsequently, we estimate the vector of structural parameters of our model on US real quarterly interest and growth rates (see Figure 1).
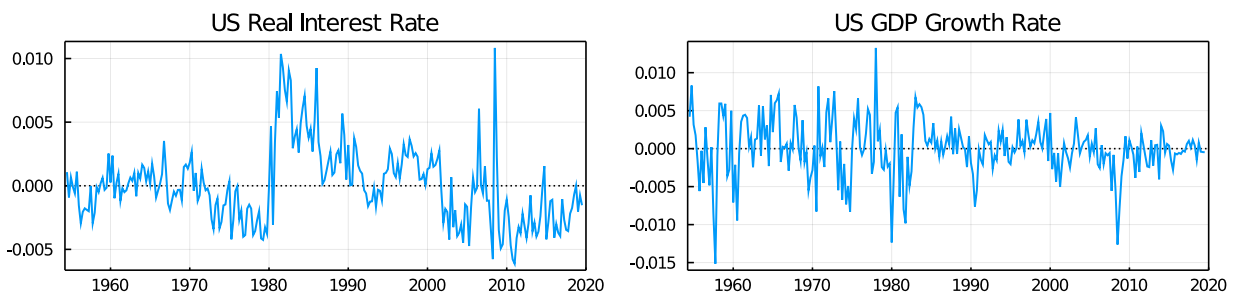

Figure 1: US Real Interest and GDP Growth Rates

Note: demeaned US real quarterly interest rate (Effective Federal Funds Rate (FF) minus Consumer Price Index (CPIAUCSL) quarterly growth rate - left pane) and real per capita gross domestic product (GDP) growth rate (A939RX0Q048SBEA - right pane). Data retrieved from FRED, Federal Reserve Bank of St. Louis, on a quarterly frequency between 1954-Q3 and 2019-Q4.

\subsection{Bayesian Extended Method of Simulated Moments}

In its original form, the EMSM estimates the vector of structural parameters of a non-linear model inferencing it indirectly from an auxiliary model with $p$ lags (Smith Jr, 1993). In other words, the EMSM introduces the following steps to find the vector of structural parameters: 
1. Simulate $h=1, \ldots, H$ sequences $\left\{y_{s}^{h}(\theta)\right\}_{s=1+p}^{S}$ from the proposed model, where $\theta \in \Theta \subset \mathbb{R}^{k}$ is the vector of structural parameters object of estimation;

2. Estimate:

$$
\widehat{\psi}_{S}^{h}(\theta)=\underset{\psi \in \Psi}{\operatorname{argmax}} \mathcal{L}\left(\left\{y_{s}^{h}(\theta)\right\} ; \psi\right)
$$

where $\mathcal{L}\left(\left\{y_{s}^{h}(\theta)\right\} ; \psi\right)$ is the quasi-log-likelihood function of an auxiliary model with parameters $\psi \in \Psi \subset \mathbb{R}^{n}$ and $p$ lags calculated on the $h$-th simulated time series $\left\{y_{s}^{h}(\theta)\right\}_{s=1+p}^{S}$;

3. Estimate:

$$
\widehat{\psi}_{T}=\underset{\psi \in \Psi}{\operatorname{argmax}} \mathcal{L}\left(\left\{x_{t}\right\} ; \psi\right)
$$

where $\mathcal{L}\left(\left\{x_{t}\right\} ; \psi\right)$ is the quasi-log-likelihood function of the auxiliary model with parameters $\psi \in \Psi \subset \mathbb{R}^{n}$ and $p$ lags calculated on the observed time series $\left\{x_{t}\right\}_{t=1+p}^{T}$;

4. The EMSM estimator of the vector of structural parameters $\theta$ is:

$$
\widehat{\theta}_{T}=\underset{\theta \in \Theta}{\operatorname{argmin}} Q(\theta)
$$

where

$$
Q(\theta)=\frac{T-p}{1+H^{-1}}\left(\widehat{\psi}_{T}-\frac{1}{H} \sum_{h=1}^{H} \widehat{\psi}_{S}^{h}(\theta)\right)^{\prime} \widehat{W}_{T}\left(\widehat{\psi}_{T}-\frac{1}{H} \sum_{h=1}^{H} \widehat{\psi}_{S}^{h}(\theta)\right)
$$

and $\widehat{W}_{T}$ is the inverse of the Newey-West sandwich estimator of the asymptotic covariance matrix of $(T-p)^{\frac{1}{2}}\left(\widehat{\psi}_{T}-\psi_{0}\right)$ (see Smith Jr, 1993, for a full explanation).

Nevertheless, we recognise that finding the minimum of the criterion function $Q(\theta)$ is unpractical in our framework because both the analytical and numerical derivatives are not feasible. With this in mind, we propose a Bayesian modification of the procedure, in which we exploit the distributional properties of the criterion function. In particular, we know that it follows a chi-squared distribution with $n-k$ degrees of freedom:

$$
Q(\theta) \sim \chi^{2}(n-k)
$$

Accordingly, we can obtain a Bayesian estimator of the vector of structural parameters through a Random Walk Metropolis-Hastings (RWMH) algorithm with acceptance probability:

$$
\omega=\min \left\{1, \frac{f\left[Q\left(\theta^{(\text {cand })}\right)\right]}{f\left[Q\left(\theta^{(j-1)}\right)\right]} \frac{g\left(\theta^{(j-1)} \mid \theta^{(\text {cand })}\right)}{g\left(\theta^{(\text {cand })} \mid \theta^{(j-1)}\right)}\right\}
$$


where $\theta^{\text {(cand) }}$ is the proposed vector of structural parameters at the $j$-th iteration, $f(x) \sim \chi^{2}(n-k)$ is the theoretical distribution of the criterion function $Q(\theta)$, and $g\left(\theta^{\text {(cand) }} \mid \theta^{(j-1)}\right)$ is a proposal distribution of the vector $\theta^{\text {(cand) }}$ given $\theta^{(j-1)}$. In other words, at each step $j$, the RWMH algorithm proposes a new vector $\theta^{\text {(cand) }}$ from the distribution $g\left(\theta^{(\text {cand })} \mid \theta^{(j-1)}\right)$, accepts $^{10}$ it with probability $\omega$ and sets $\theta^{(j)}=\theta^{\text {(cand) }}$.

Overall, if the model is an adequate representation of the observed time series, the RWMH algorithm generates a sequence of structural parameters $\left\{\theta^{(j)}\right\}_{j=1}^{J}$ such that:

$$
Q\left(\theta^{(j)}\right) \sim \chi^{2}(n-k) \quad \forall j=1, \ldots, J
$$

as required by the EMSM.

\subsection{Data and Estimation Settings}

The main objective of this work is to analyse business cycles fluctuations. As a result, we limit our estimate of the vector of structural parameters $\theta$ on the demeaned quarterly time series of US real interest and growth rates (see Figure 1). Our model cannot - and does not even want to - reproduce the long-term growth properties of real economies. Accordingly, we focus only on the demeaned time series as their averages capture this characteristic of economic systems. With this in mind, we compare the demeaned US data with the demeaned average deposit interest rate and the demeaned aggregate production growth rate of the simulated economy.

We select as an auxiliary model a Vector Autoregressive (VAR) model without the constant term. As stated before, this coefficient captures the long-term growth properties of real economies, which goes beyond the scope of this work. However, it is a relatively harmless decision, since it does not affect the estimation of the other parameters of the VAR. Moreover, we choose this model because it does not require any specific assumption on the interdependence of variables. Lastly, the Akaike (AIC) and the Bayesian (BIC) information criteria allow us to automatically select the optimal lag order for the observed time series. In summary, we chose as an auxiliary model a $\operatorname{VAR}(3)$ model without the constant term, which we estimate on the demeaned simulated and observed time series.

The structural parameters of the model are the number of agents $n_{h}$, $n_{i}$ and $n_{f}$, the discount factor of the households $\beta$, the search probabilities $\pi_{h}$ and $\pi_{f}$, the production function coefficient $\alpha$, and the exploration range $\gamma$. On the one hand, we set the number of households $n_{h}=1000$ to have a sufficiently high level of interactions between agents and allow the emergence

\footnotetext{
${ }^{10}$ Rejects it with probability $1-\omega$ and sets $\theta^{(j)}=\theta^{(j-1)}$.
} 
of endogenous dynamics ${ }^{11}$. At the same time, we fix the number of firms $n_{f}=1000$, since we assume a one-to-one relation with the households in the initialization phase of the simulation (see Section 2.3). On the other hand, we estimate the remaining parameters through the modified version of the EMSM introduced before.

With regards to the proposal distribution, we assume that each parameter $\theta_{z}^{\text {(cand) }}$ is drawn independently from a uniform distribution centred on the last accepted value $\theta_{z}^{(j-1)}$, namely:

$$
\theta_{z}^{(\text {cand })} \sim g\left(\theta_{z}^{\text {(cand) }} \mid \theta_{z}^{(j-1)}\right)=U\left(\theta_{z}^{(j-1)}-\Delta_{z}, \theta_{z}^{(j-1)}+\Delta_{z}\right)
$$

where $\Delta_{z}=\left(M_{z}-m_{z}\right) / 20$. Moreover, we constrain the upper and lower bounds of the proposal distribution on the subsets:

$$
\theta_{z}^{(j-1)}-\Delta_{z} \in\left[m_{z}, M_{z}-2 \Delta_{z}\right] \quad \theta_{z}^{(j-1)}+\Delta_{z} \in\left[m_{z}+2 \Delta_{z}, M_{z}\right]
$$

where the parameters $m_{z}$ and $M_{z}$ lie inside a reasonable set of values (see Table 1).

Table 1: Proposal Distributions of Structural Parameters

\section{Households}

\begin{tabular}{ccc}
\hline$\theta_{z}$ & $m_{z}$ & $M_{z}$ \\
\hline$\pi_{h}$ & $10^{-4}$ & 0.5 \\
$\beta$ & 0.99 & 0.999 \\
\hline
\end{tabular}

\section{Intermediaries}

\begin{tabular}{ccc}
\hline$\theta_{z}$ & $m_{z}$ & $M_{z}$ \\
\hline$\gamma$ & $10^{-4}$ & 0.5 \\
$n_{i}$ & 4 & 24 \\
\hline
\end{tabular}

Firms

\begin{tabular}{ccc}
\hline$\theta_{z}$ & $m_{z}$ & $M_{z}$ \\
\hline$\pi_{f}$ & $10^{-4}$ & 0.5 \\
$\alpha$ & 0.05 & 0.95 \\
\hline
\end{tabular}

Lastly, with regards to the Random Walk Metropolis-Hastings algorithm, we run a Markov Chain Monte Carlo (MCMC) of length $J=5 \times 10^{4}$ and keep the last $\mathbb{J}=\left[1 \times 10^{4}, J\right]$ extractions as estimation subsample. To let the simulated economy converge to its pseudo-steady-state, we simulate $H=20$ sequences of length $S=5261$ for each proposal vector of structural parameters $\left\{y_{s}^{h}\left(\theta^{(\text {cand })}\right)\right\}_{s=1+p}^{S}$ and calculate the criterion function $Q\left(\theta^{\text {(cand })}\right)$ on the last $T=261$ observations. Lastly, given the number of parameters of the demeaned $\operatorname{VAR}(3)$ model $(n=15)$ and the length of the vector of structural parameters $(k=6)$, the criterion function follows a chi-squared distribution with $n-k=9$ degrees of freedom. In light of this, we set the acceptance rate $\omega$ (see 36 ) accordingly (see Table 2 for a summary).

\subsection{Estimation Results}

In Figure 2, we plot the marginal posterior distributions of the structural parameters, while Table 3 reports their summary statistics. The $90 \%$ confi-

\footnotetext{
${ }^{11}$ We could have set a higher number of households, but it would just have behaved as a scale parameter.
} 
Table 2: Estimation Settings

\section{Criterion Function}

\begin{tabular}{l} 
Auxiliary model: $\operatorname{VAR}(3)$ without constant term \\
Number of parameters of the auxiliary model: $n=15$ \\
Number of structural parameters: $k=6$ \\
Criterion function distribution: $Q(\theta) \sim \chi^{2}(9)$ \\
\hline
\end{tabular}

Random Walk Metropolis-Hastings Algorithm

Length of Markov Chain Monte Carlo: $J=5 \times 10^{4}$

Estimation subsample: $\mathbb{D}=\left\{j: 10^{4}<j \leq J\right\}$

\section{Simulated Sequences}

Number of simulations: $H=20$

Length of each simulation: $S=5261$

Length of observed time series: $T=261$

Estimation subsample: $\mathbb{S}=\{s: S-T<s \leq S\}$

dence intervals indicate that the RWMH algorithm does not reach the estimation boundaries at least $90 \%$ of the time. As a result, we can safely affirm that the domains of the unconditional proposal distributions are sufficiently ample and our estimates of the model are not biased. In fact, the MCMC is not upper and lower constrained by our initial assumptions (see Table 1).

The search probabilities $\pi_{h}$ and $\pi_{f}$ play a fundamental role in defining the dynamics of business cycles. Their median values $\left(\pi_{h}=0.10, \pi_{f}=\right.$ 0.09 ) indicate that real-world economies are characterized by a high level of persistence in both the deposit and credit markets. In other words, those parameters suggest that switching costs are far from being negligible in the real financial sector.

At the same time, the discount factor of the households $\beta$ is consistent with the observed one. The average US quarterly real interest rate $(0.0033)$ is close to the implicit steady-state value of simulations (0.0043) and lies within the $90 \%$ confidence interval $(0.0029,0.0058)^{12}$.

On the contrary, the exploration range $\gamma$, the number of intermediaries $n_{i}$ and the production coefficient $\alpha$ seem to follow a bimodal distribution. Accordingly, we investigate this aspect by dividing our simulations into two separate subsets, namely maximizing the log-likelihood of a two-component

\footnotetext{
${ }^{12}$ The steady-state value of capital $\bar{k}$ implies: $\bar{r}=\frac{1-\beta}{\beta}$ (see 5 ).
} 

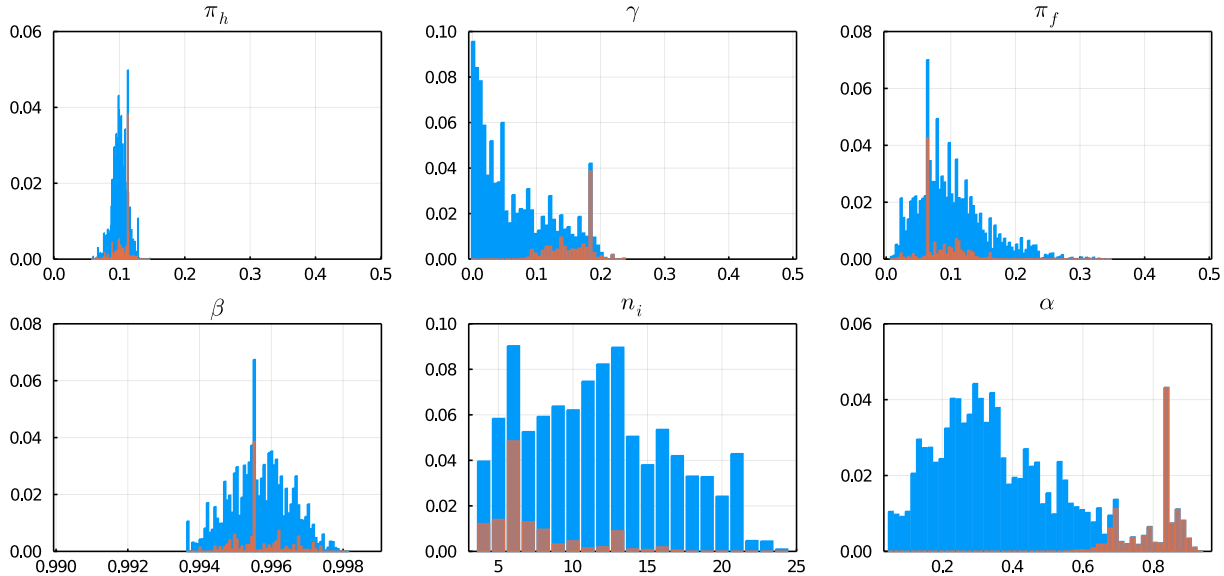

Figure 2: Marginal Posterior Distributions

Note: marginal posterior distributions of structural parameters (blue bars). Red bars highlight the alternative regime, namely the smaller subset of a two-component trivariate normal mixture on the structural parameters $n_{i}, \gamma$ and $\alpha$.

trivariate normal mixture on the parameters $n_{i}, \gamma$ and $\alpha$.

Our analysis indicates two distinct regimes (see Figure 2). On the one hand, the standard situation exhibits a large number of intermediaries $\left(n_{i}=\right.$ $12)$ lending to firms with common production technology $(\alpha=0.32)$. Moreover, the exploration range $(\gamma=0.04)$ indicates that banks explore only a small neighbourhood of their current strategies, as an excessive deviation would be detrimental for their profits. On the other hand, in the alternative regime, few intermediaries $\left(n_{i}=6\right)$ lend to firms characterised by a quasilinear production function $(\alpha=0.85)$. Banks can also explore a larger set of strategies $(\gamma=0.17)$ because the increase in market concentration generates higher profits on average. That, in turn, allows intermediaries to take more risks while setting their prices. On the contrary, the search probabilities $\pi_{h}$ and $\pi_{f}$ and the discount factor of the households $\beta$ are not statistically different in the two subsets.

Lastly, we perform an over-identification test to asses if the estimated parameters are not statistically different from the observed ones. In Figure 3 , we compare the empirical distribution of the simulated criterion function against its theoretical counterpart. As it emerges from the plot, we must reject the null hypothesis and question whether the model is an adequate representation of the observed time series. Indeed, the simulated criterion function is always above the $1 \%$ significance level.

On the one hand, we are not excessively surprised by this result as the model comprises only a stylised version of the financial sector. Moreover, it does not take into account other crucial aspects of real economies as, 
Table 3: Summary Statistics of Structural Parameters

\begin{tabular}{|c|c|c|c|c|c|c|}
\hline \multirow[b]{2}{*}{ Parameter } & \multicolumn{2}{|c|}{$\begin{array}{l}\text { Complete } \\
(N=40000)\end{array}$} & \multicolumn{2}{|c|}{$\begin{array}{l}\text { Standard } \\
(N=35110)\end{array}$} & \multicolumn{2}{|c|}{$\begin{array}{l}\text { Alternative } \\
\quad(N=4890)\end{array}$} \\
\hline & Median & $90 \%$ C.I. & Median & $90 \%$ C.I. & Median & $90 \%$ C.I. \\
\hline \multirow{2}{*}{$\pi_{h}$} & \multirow{2}{*}{0.1010} & 0.0830 & \multirow{2}{*}{0.1003} & 0.0829 & \multirow{2}{*}{0.1106} & 0.0885 \\
\hline & & 0.1176 & & 0.1176 & & 0.1172 \\
\hline \multirow{2}{*}{$\beta$} & \multirow{2}{*}{0.9957} & 0.9942 & \multirow{2}{*}{0.9957} & 0.9942 & \multirow{2}{*}{0.9955} & 0.9947 \\
\hline & & 0.9971 & & 0.9971 & & 0.9971 \\
\hline \multirow{2}{*}{$\gamma$} & \multirow{2}{*}{0.0491} & 0.0046 & \multirow{2}{*}{0.0414} & 0.0039 & \multirow{2}{*}{0.1682} & 0.0997 \\
\hline & & 0.1870 & & 0.1646 & & 0.1911 \\
\hline \multirow{2}{*}{$n_{i}$} & \multirow{2}{*}{11} & 5 & \multirow{2}{*}{12} & 5 & \multirow{2}{*}{6} & 4 \\
\hline & & 21 & & 21 & & 13 \\
\hline \multirow{2}{*}{$\pi_{f}$} & \multirow{2}{*}{0.0927} & 0.0321 & \multirow{2}{*}{0.0947} & 0.0302 & \multirow{2}{*}{0.0777} & 0.0418 \\
\hline & & 0.2099 & & 0.2132 & & 0.1414 \\
\hline \multirow{2}{*}{$\alpha$} & \multirow{2}{*}{0.3456} & 0.1268 & \multirow{2}{*}{0.3180} & 0.1254 & \multirow{2}{*}{0.8473} & 0.6778 \\
\hline & & 0.8473 & & 0.5999 & & 0.9004 \\
\hline
\end{tabular}

Note: median and $90 \%$ confidence intervals of structural parameters. Values for the complete MCMC sequence, and divided between standard and alternative regimes. The two subsets maximize the log-likelihood of a two-component trivariate normal mixture on the parameters $n_{i}, \gamma$ and $\alpha$.

for example, goods and labour markets. On the other hand, the impulseresponse functions of the simulated time series provide a good replication of the observed ones (see Figure 4). In particular, the model reproduces the response of the economy to an exogenous increase in the risk-free interest rate relatively well (Figure 4 - top panes). Conversely, the simulated time series cannot replicate the short-term fall in the real interest rate related to an exogenous rise in the aggregate production growth rate (Figure 4 bottom panes). Accordingly, that could be the main reason behind the poor performance of the over-identification test.

Overall, we must reject the null hypothesis that the estimated parameters are not statistically different from the observed ones. Nevertheless, the model offers a good replication of the response of the US economy to an exogenous increase in the risk-free interest rate. With this in mind, we restrict the analysis of business cycles on this aspect, focusing on the aggregate dynamic of the system and the behaviour of banks.

\section{Endogenous Cycles}

In this section, we investigate the dynamic of the endogenous business cycles generated by the model, focusing on the response of the economy to changes in the deposit and credit markets interest rates. Specifically, we set the 


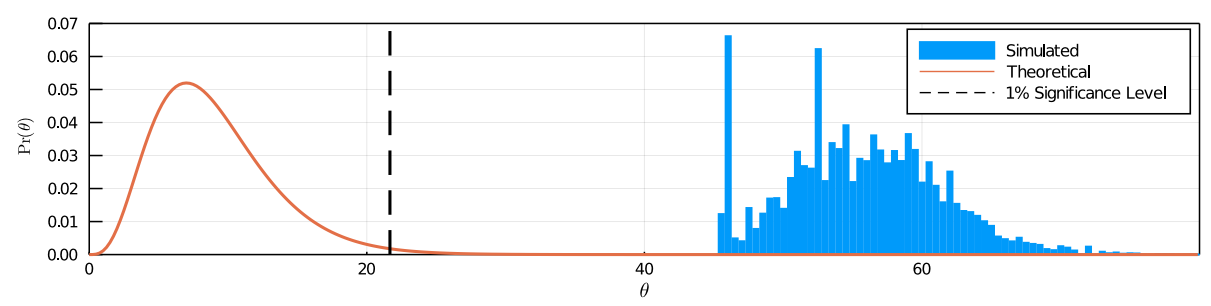

Figure 3: Overidentification Test

Simulated and Theoretical Criterion Function Distributions

values of the structural parameters equal to the medians of the marginal posterior distributions (see Table 3, first column) and run 1000 simulations of length $S=5000+T \cdot H$ of the model ${ }^{13}$. Subsequently, we analyse the dynamics of the last $T \cdot H$ observations ${ }^{14}$.

As in real-world data, the unconditional distribution of the aggregate production growth rate is left-skewed (Sichel, 1993). In other words, the simulated economy alternates periods of sustained growth with sharp recessions (Figure 5, left pane). On the one hand, the large-scale closure of credit lines during financial crises damages the information capital of intermediaries. As a result, banks' allocative efficiency shrinks, and aggregate production decreases drastically. On the other hand, the process of new credits allocation need time and generates periods of sustained and positive growth. At the same time, the unconditional distribution of the deposit market interest rate is right-skewed (Figure 5, central pane). Indeed, it is lower bounded at zero, and the periods of high returns are relatively rare. Lastly, banks' profits are positive most of the time and account for $20 \%$ of total production on average (Figure 5, right pane). Given that, the lack of stock-flow consistency does not seem to introduce a significant distortion in our model. In fact, the financial sector as a whole is a net receiver of external resources only $0.1 \%$ of the time.

With regards to business cycle fluctuations, we plot the cross-correlations of selected time series with the deposit market interest rate ${ }^{15}$ in Figure 6. As expected, past increases in the level of aggregate capital reduce the deposit market interest rate because of the decreasing marginal productivity of the production function. On the contrary, higher returns promote savings, thus leading to periods of over-investment and sustained growth. In

\footnotetext{
${ }^{13}$ Smith $\operatorname{Jr}(1993)$ states that the statistics obtained from $H$ simulations of length $T$ or one simulation of length $T \cdot H$ are equivalent.

${ }^{14}$ As before, we remove the first 5000 observations to let the model converge to its pseudo-steady-state.

${ }^{15}$ The time series included are: logarithm of aggregate capital, deposit and credit markets interest rates, logarithm of aggregate production, unallocated over total capital, banks' profit over aggregate production. The time series have been pre-whitened to identify significant cross-correlations.
} 

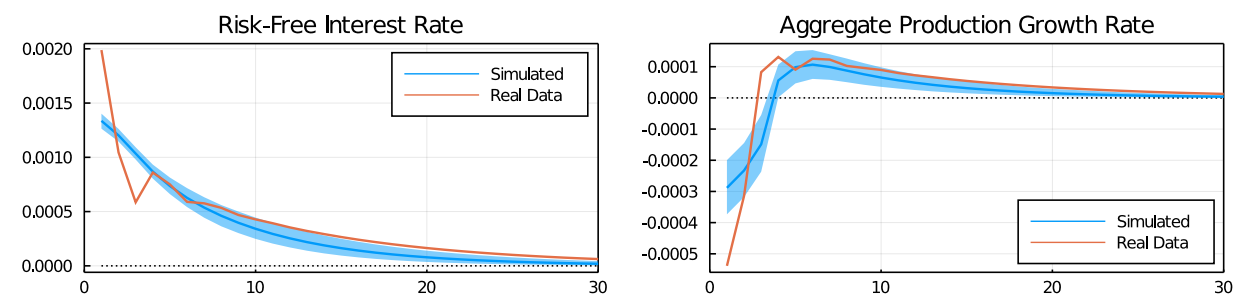

(a) Exogenous Increase in Risk-Free Interest Rate
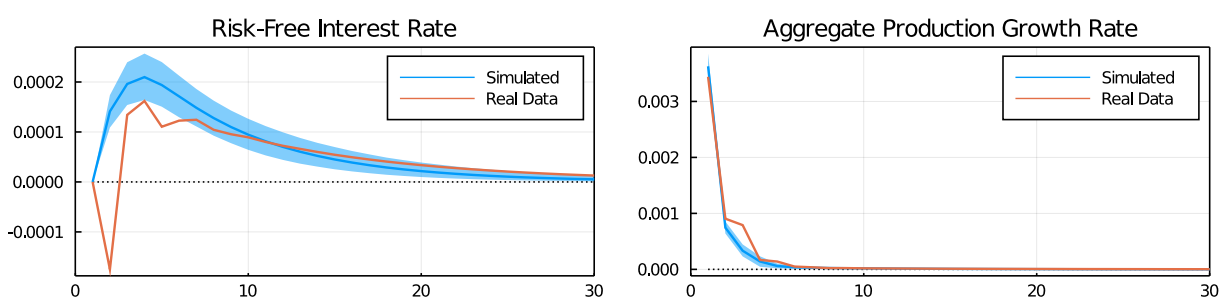

(b) Exogenous Increase in Aggregate Production Growth Rate

Figure 4: Impulse-Response Functions

Note: impulse-response functions of an exogenous increase in the risk-free interest rate (top panes) and aggregate production growth rate (bottom panes). Averages and $90 \%$ confidence intervals built on 1000 simulations. Values of the structural parameters equal to the medians of the marginal posterior distributions (see Table 3, first column). Order of Cholesky decomposition: from interest to growth rates.

fact, aggregate production follows capital in the medium and long run, since the latter is the only factor of production in the economy. Conversely, an exogenous increase in the deposit market interest rate lowers aggregate production in the short run. In particular, higher returns prompt the immediate reallocation of capital by the households without giving banks the time to adjust their portfolios of credits. As a result, new loans do not compensate the closed ones in the short-term, thus reducing aggregate production and raising unallocated capital.

Lastly, past increases in the credit market interest rate are positively related to current returns on deposits. Moreover, also banks profits follow a similar pattern. In other words, business cycles seem to begin in the credit market, namely when financial intermediaries start asking higher interest rates to firms to raise their profits. Nevertheless, the competition between banks slowly forces them to pass on the additional income to households. That, in turn, increases the deposit market interest rate and promotes capital accumulation and long-term aggregate production. But the opposite is also true: when intermediaries transfer to households the losses arising from an excessive easing of credit, the simulated economy falls into a prolonged recession. In light of this, our model confirms the importance of banks' 

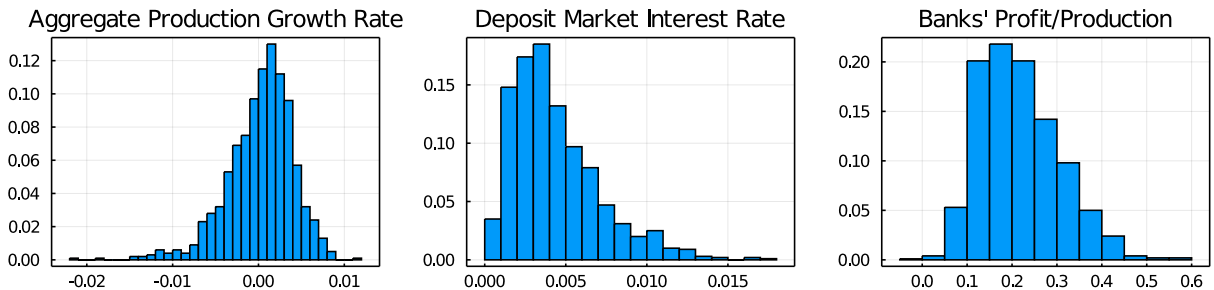

Figure 5: Unconditional Distributions

Note: unconditional distributions of aggregate production quarterly growth rate (left pane), deposit market interest rate (central pane) and aggregate banks' profit over production (right pane). Histograms built on the last observation of 1000 simulations. Values of the structural parameters equal to the medians of the marginal posterior distributions (see Table 3, first column).

search for profits in generating endogenous business cycles. Specifically, the competition between intermediaries can promote both profitable and poor strategies on the credit market, whose effects on the real economy emerge only when the gains and losses are transferred to the households.

We reassess our results estimating a VAR model on the simulated time series and calculating the impulse-response functions of an exogenous increase in the deposit and credit market interest rates $^{16}$ (Figure 7).

As expected, a higher interest rate in the deposit market promotes capital accumulation and aggregate production in the long-term (Figure 7, top panes). Nevertheless, the shock boosts capital reallocation by the households in the short-term, without giving banks the time to adjust their portfolios of credits. As a result, new loans do not compensate the closed ones, thus reducing aggregate production and raising unallocated capital. Overall, banks' profits drop because of the higher costs of savings and the decrease in allocative efficiency.

Similarly, an increase in the credit market interest rate reduces aggregate production in the short-term (Figure 7, bottom panes). In fact, firms' credit demand shrinks, unallocated capital raises, and the allocative efficiency of banks decreases. However, when intermediaries start to transfer the additional profits to depositors because of competition, the economy begins to recover. In particular, the additional capital allows banks to extend credit to a larger set of firms, some of which are willing to accept the new interest rate. Overall, aggregate production does not only recover but also surpasses the pre-crisis level in the medium-term. In light of this, our model highlights the intertemporal trade-off of credit easing. While a reduction

\footnotetext{
${ }^{16}$ The time series included in the estimations are: logarithm of aggregate capital, deposit and credit markets interest rates, logarithm of aggregate production, unallocated over total capital, banks' profits over aggregate production. Lag selection is based on AIC. The orthogonal errors of the impulse response functions follow the actual order of the model.
} 

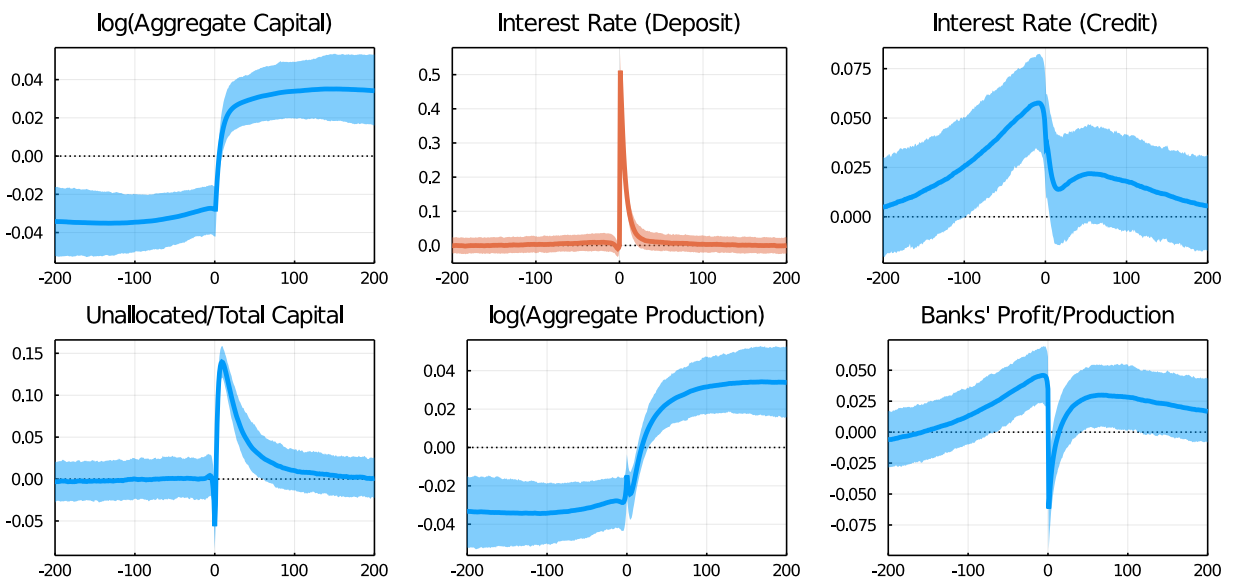

Figure 6: Cross-Correlogram of Deposit Market Interest Rate

Note: cross-correlations of selected time series with deposit market interest rate (pre-whitened). Averages and 90\% confidence intervals built on 1000 simulations. Values of the structural parameters equal to the medians of the marginal posterior distributions (see Table 3, first column).

in lending requirements increases the economic activity in the short run, it undermines long-term development as losses fall ultimately on households and consumers.

\section{Concluding Remarks}

This paper has developed and estimated a simple ABM of bank-intermediated credit flows in which information and matching imperfections give rise to search frictions and resources misallocation. We have shown that credit cycles arise endogenously because of banks' search for profits. The key driving mechanism is a pure competition effect, as financial intermediaries struggle to increase their profits through the activation and termination of credit and deposit relationships at varying interest rates to attract both firms and depositors.

Overall, our model highlights the intertemporal trade-off of unnecessary credit easing. While a reduction in lending requirements increases the economic activity in the short run, it undermines long-term growth perspectives. Since losses fall ultimately on the households, that discourages capital accumulation and aggregate production in the long run. With this in mind, even if we have not explicitly modelled banks' equity, it seems to play a pivotal role in avoiding the transferring of financial distress to consumers and preventing the beginning of long-lasting recessions. In that sense, our results support the efforts made by policymakers to tighten the capital requirements of financial institutions (see, among others, Basel Committee on Banking 
Supervision, 2017).

The model can be extended in a number of directions to consider important issues. First, we have so far ignored agency frictions. The probability a long-run loan contract is severed - and, therefore, the extent of credit reallocation - is in general related to the effort choice of the borrower in servicing his debt, as well as on the risk appetite of the lender. Incorporating moral hazard problems associated to the level of net worth of agents are therefore likely to sensibly improve the explanatory capability of our model.

For reasons of tractability we have abstracted from the labour market or any other kind of physical production factors. As shown e.g. in Wasmer and Weil (2004), general equilibrium feedbacks between the markets for finance and productive inputs can magnify the response of the economy to exogenous shocks through a financial accelerator mechanism. Such an improvement could allow us to complement the story we offer here with an analysis of the way disruptions in financial markets affect unemployment and economic activity, and vice-versa, by exploring the issues of how credit misallocation interacts with labour misallocation (Delli Gatti et al., 2012) and income distribution (Dosi et al., 2013).

Finally, an interesting extension would be that of studying the effects of competition policies or taxation in steering intermediaries' behaviour from individual to aggregate optimal strategies. 

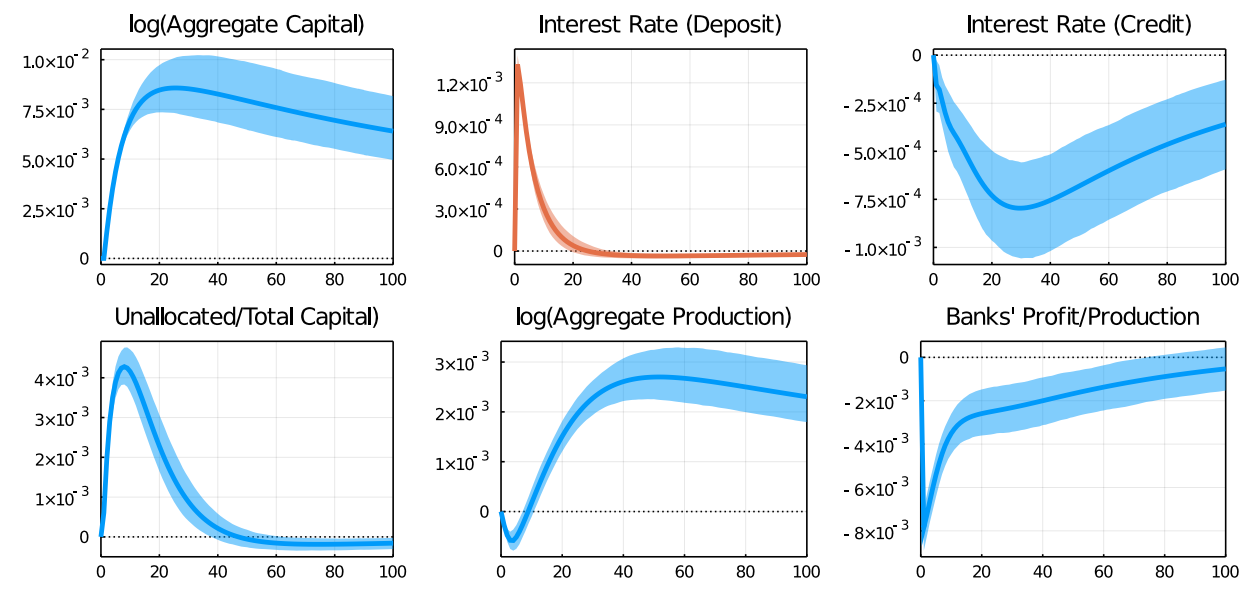

(a) Exogenous Increase in Deposit Market Interest Rate
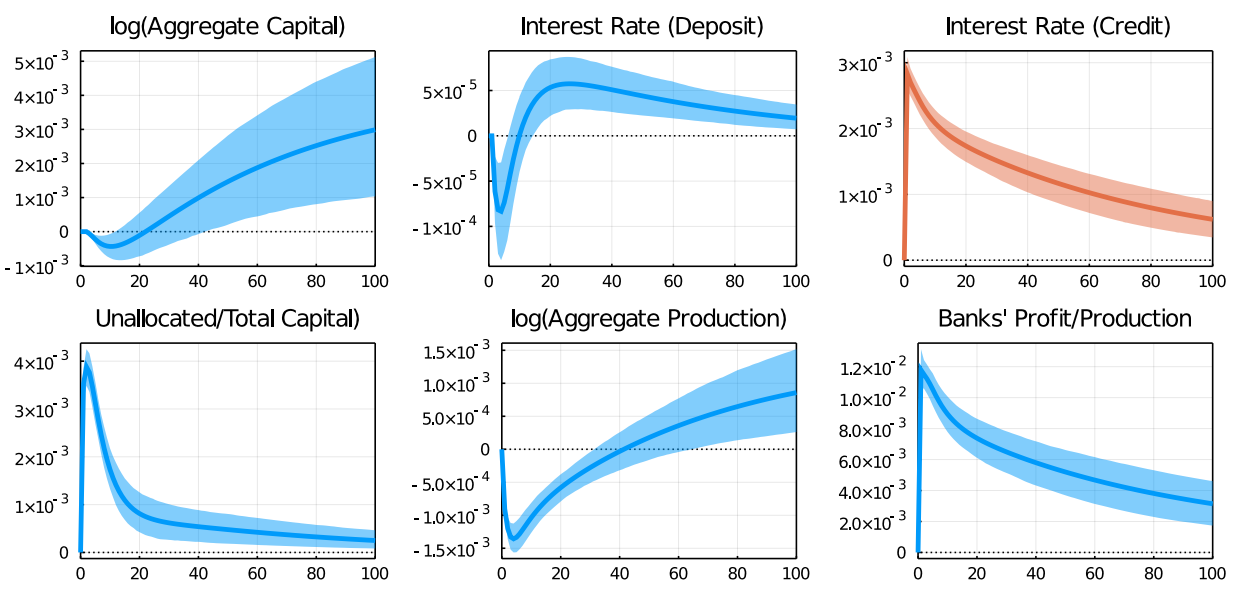

(b) Exogenous Increase in Credit Market Interest Rate

Figure 7: Impulse-Response Functions

Note: impulse-response functions of an exogenous increase in the deposit (top panes) and credit (bottom panes) markets interest rates. Averages and 90\% confidence intervals built on 1000 simulations. Values of the structural parameters equal to the medians of the marginal posterior distributions (see Table 3, first column). 


\section{References}

Bargigli, L., Riccetti, L., Russo, A. and Gallegati, M. (2020), 'Network calibration and metamodeling of a financial accelerator agent based model', Journal of Economic Interaction and Coordination 15(2), 413-440.

Basel Committee on Banking Supervision (2017), 'Basel III: Finalising postcrisis reforms'.

Becsi, Z., Li, V. E. and Wang, P. (2013), 'Credit mismatch and breakdown', European Economic Review 59, 109-125.

Bernanke, B. and Gertler, M. (1989), 'Agency Costs, Net Worth, and Business Fluctuations', The American Economic Review 79(1), 14-31.

Brunetti, M., Ciciretti, R. and Djordjevic, L. (2016), 'The determinants of household's bank switching', Journal of Financial Stability 26, 175-189.

Brunnermeier, M. K., Eisenbach, T. M. and Sannikov, Y. (2012), Macroeconomics with financial frictions: A survey, Technical report, National Bureau of Economic Research.

Chakravarty, S., Feinberg, R. and Rhee, E.-Y. (2004), 'Relationships and individuals' bank switching behavior', Journal of Economic Psychology $\mathbf{2 5}(4), 507-527$.

Chen, Z. and Lux, T. (2018), 'Estimation of sentiment effects in financial markets: A simulated method of moments approach', Computational Economics 52(3), 711-744.

Christiano, L. and Ikeda, D. (2011), Government policy, credit markets and economic activity, Technical report, National Bureau of Economic Research.

Covas, F. and Haan, W. J. D. (2011), 'The Cyclical Behavior of Debt and Equity Finance', American Economic Review 101(2), 877-899.

Delli Gatti, D., Di Guilmi, C., Gaffeo, E., Giulioni, G., Gallegati, M. and Palestrini, A. (2005), 'A new approach to business fluctuations: heterogeneous interacting agents, scaling laws and financial fragility', Journal of Economic Behavior \& Organization 56(4), 489-512.

Delli Gatti, D., Gallegati, M., Greenwald, B. C., Russo, A. and Stiglitz, J. E. (2012), 'Mobility constraints, productivity trends, and extended crises', Journal of Economic Behavior 63 Organization 83(3), 375-393.

Delli Gatti, D. and Grazzini, J. (2019), Rising to the Challenge: Bayesian Estimation and Forecasting Techniques for Macroeconomic Agent-Based Models, CESifo Working Paper Series 7894, CESifo. 
Den Haan, W. J., Ramey, G. and Watson, J. (2003), 'Liquidity flows and fragility of business enterprises', Journal of Monetary Economics 50(6), 1215-1241.

Diamond, P. A. (1990), 'Pairwise credit in search equilibrium', The Quarterly Journal of Economics 105(2), 285-319.

Dosi, G., Fagiolo, G., Napoletano, M. and Roventini, A. (2013), 'Income distribution, credit and fiscal policies in an agent-based Keynesian model', Journal of Economic Dynamics and Control 37(8), 1598-1625.

Fagiolo, G., Dosi, G. and Gabriele, R. (2004), 'Matching, bargaining, and wage setting in an evolutionary model of labor market and output dynamics', Advances in Complex Systems 7(02), 157-186.

Fagiolo, G., Guerini, M., Lamperti, F., Moneta, A. and Roventini, A. (2019), Validation of agent-based models in economics and finance, in 'Computer Simulation Validation', Springer, pp. 763-787.

Foglia, A., Hancock, D., Alessandri, P., Bayliss, T., Boissay, F., Christensen, I. and Lago, R. (2011), 'The transmission channels between the financial and real sectors: a critical survey of the literature', Basel Committee on Banking Supervision Working Papers (18).

Franke, R. (2009), 'Applying the method of simulated moments to estimate a small agent-based asset pricing model', Journal of Empirical Finance 16(5), 804-815.

Franke, R. and Westerhoff, F. (2012), 'Structural stochastic volatility in asset pricing dynamics: Estimation and model contest', Journal of Economic Dynamics and Control 36(8), 1193-1211.

Gaffeo, E., Delli Gatti, D., Desiderio, S. and Gallegati, M. (2008), 'Adaptive microfoundations for emergent macroeconomics', Eastern Economic Journal 34(4), 441-463.

Gaffeo, E., Gallegati, M. and Gostoli, U. (2015), 'An agent-based "proof of principle" for Walrasian macroeconomic theory', Computational and Mathematical Organization Theory 21(2), 150-183.

Gilli, M. and Winker, P. (2003), 'A global optimization heuristic for estimating agent based models', Computational Statistics 83 Data Analysis 42(3), 299-312.

Gottfries, N. (1991), 'Customer markets, credit market imperfections and real price rigidity', Economica pp. 317-323. 
Grazzini, J. and Richiardi, M. (2015), 'Estimation of ergodic agent-based models by simulated minimum distance', Journal of Economic Dynamics and Control 51, 148-165.

Grazzini, J., Richiardi, M. G. and Tsionas, M. (2017), 'Bayesian estimation of agent-based models', Journal of Economic Dynamics and Control 77, 2647.

Greenwald, B. C. and Stiglitz, J. E. (1993), 'Financial market imperfections and business cycles', The Quarterly Journal of Economics 108(1), 77-114.

Guerini, M., Napoletano, M. and Roventini, A. (2018), 'No man is an island: The impact of heterogeneity and local interactions on macroeconomic dynamics', Economic Modelling 68, 82-95.

Jaffee, D. M. and Russell, T. (1976), 'Imperfect information, uncertainty, and credit rationing', The Quarterly Journal of Economics 90(4), 651-666.

Kim, M., Kliger, D. and Vale, B. (2003), 'Estimating switching costs: the case of banking', Journal of Financial Intermediation 12(1), 25-56.

Kiser, E. K. (2002), 'Predicting household switching behavior and switching costs at depository institutions', Review of Industrial Organization 20(4), 349-365.

Kiyotaki, N. and Moore, J. (1997), 'Credit cycles', Journal of Political Economy 105(2), 211-248.

Lux, T. and Zwinkels, R. C. (2018), Empirical validation of agent-based models, in 'Handbook of computational economics', Vol. 4, Elsevier, pp. 437488.

Mandes, A. and Winker, P. (2017), 'Complexity and model comparison in agent based modeling of financial markets', Journal of Economic Interaction and Coordination 12(3), 469-506.

Platt, D. (2020), 'A comparison of economic agent-based model calibration methods', Journal of Economic Dynamics and Control 113, 103859.

Recchioni, M. C., Tedeschi, G. and Gallegati, M. (2015), 'A calibration procedure for analyzing stock price dynamics in an agent-based framework', Journal of Economic Dynamics and Control 60, 1-25.

Riccetti, L., Russo, A. and Gallegati, M. (2015), 'An agent based decentralized matching macroeconomic model', Journal of Economic Interaction and Coordination 10(2), 305-332. 
Schularick, M. and Taylor, A. M. (2012), 'Credit booms gone bust: monetary policy, leverage cycles, and financial crises, 1870-2008', The American Economic Review 102(2), 1029-1061.

Sharpe, S. A. (1997), 'The effect of consumer switching costs on prices: A theory and its application to the bank deposit market', Review of Industrial Organization 12(1), 79-94.

Sichel, D. E. (1993), 'Business cycle asymmetry: a deeper look', Economic Inquiry 31(2), 224-236.

Smith Jr, A. A. (1993), 'Estimating nonlinear time-series models using simulated vector autoregressions', Journal of Applied Econometrics 8(S1), S63S84.

Stiglitz, J. E. (2015), Towards a General Theory of Deep Downturns, Working Paper 21444, National Bureau of Economic Research.

Stiglitz, J. E. and Weiss, A. (1981), 'Credit rationing in markets with imperfect information', The American Economic Review 71(3), 393-410.

Tesfatsion, L. (2006), 'Agent-based computational economics: A constructive approach to economic theory', Handbook of Computational Economics 2, 831-880.

Wasmer, E. and Weil, P. (2004), 'The macroeconomics of labor and credit market imperfections', The American Economic Review 94(4), 944-963.

Winker, P., Gilli, M. and Jeleskovic, V. (2007), 'An objective function for simulation based inference on exchange rate data', Journal of Economic Interaction and Coordination 2(2), 125-145. 